\title{
SPATIO-TEMPORAL ANALYSIS OF NATURAL HUMAN HABITABILITY ENVIRONMENT ALONG THE COASTAL TALUKS OF TAMIL NADU, INDIA
}

\author{
S. Nitheshnirmal ${ }^{1}$, S. Abdul Rahaman ${ }^{1,}$, A. Balasundareshwaran ${ }^{1}$, K. Nivedita Priyadarshini ${ }^{1}$, K. Balasubramani ${ }^{2}$, K. \\ Kumaraswamy ${ }^{1}$
}
${ }^{1}$ Department of Geography, Bharathidasan University, Tiruchirappalli, Tamil Nadu - (nirmalgsarath, abdulatgeo )@ gmail.com ${ }^{2}$ Assistant Professor, Department of Geography, Central University of Tamil Nadu, India

\section{Commission V, SS: Infrastructure and Development Planning}

\begin{abstract}
KEY WORDS: Human habitability, Land Surface Temperature, Impervious surfaces, Natural Human habitation Environment
\end{abstract} Suitability Index (NHESI), Climate change, Vegetation coverage.

\begin{abstract}
:
In this present world, due to the increasing adverse effect of anthropological activities on the natural environment causes a large scale environmental degradation which directly reduces the suitable natural environment for human habitation. As a consequence, in recent years, human realised the need for a favourable natural environment which is adoptable for habitation. In this present study, some of the following five criterions such as Land Surface Temperature (LST), vegetation coverage, impervious surface, wetness and water condition derived from the remotely sensed data were used to evaluate the Natural Human habitation Environment Suitability Index (NHESI) along the coastal taluks of Tamil Nadu. Landsat-7 (ETM+) images and Landsat-8 (OLI/TIRS) images with a spatial resolution of $30 \mathrm{~m}$ have been used to derive the evaluation factors of NHESI for the year of 2000 and 2018 . Multi Criteria Evaluation (MCE) based Analytical Hierarchical Process (AHP) and fuzzy linear membership has been used in this study to evaluate the weighs and ratings of each criterion and its classes. The best NHESI is seen in 2000 where a total area of about 13902.9 $\mathrm{km}^{2}$ comes under the habitable region, against an area of $7726.9 \mathrm{~km}^{2}$ in 2018 . The study area is further classified into moderately habitable, marginally habitable and uninhabitable regions. This study clearly indicates the degradation of the natural environmental conditions for human habitation. This kind of habitability study will help the researchers, decision makers and government agencies in creating awareness and adopting policies in the spatial planning of human land utilization for habitability.
\end{abstract}

\section{HUMAN HABITABILITY ANALYSIS}

\subsection{Introduction}

The study of human settlements gained interest with the ideas of Greek Scholar Doxiadis, as his concept of "Ekistics - Science of human settlement" was a subject undergoing intense study in the fields of architecture, geography, planning and other subjects (Doxiadis, 1968; Choguill, 1996). Doxiadis (1970) stated that the quality of man's relationship with the natural environment will not only increase the psychological and mental health of the society, but also influences their socioeconomic development. Human habitations have a conceptual relationship with the natural environment, which plays a major role in determining the human lives and their activities. In recent years, the rapid growth of population and urbanisation in India and its coastal cities have influenced the occupance of more geographical space both within urban and rural spaces. Since the development of anthropocene, humans attached themself more with the natural environment in order to derive their basic needs and valuable natural products ( Goldewijk \& Ramankutty, 2004). But later on, human activities during the last few decades have greatly modified the natural environment and also caused adverse effects on the climate system causing a massive global change. The development of human settlements in the coastal regions is also more rapid than the hinterlands (Neumann et al., 2015). This rapid increase in the population and human settlements resulted in the degradation of natural environment in which human settled. Due to which, in the 2030 Agenda of the United Nations (UN), 17 Sustainable Development Goals (SDG) were signed by the UN member countries, which urge the need for inclusive, safe, resilient and sustainable human settlements (UN, 2016). The development of sustainable human settlement is made only by improving the social, economic and environmental quality of human settlements and, the living and working environments of all people, in particular the urban and rural people (UNO, 1992). This made the researchers and the scientists of this decade to concentrate mainly on the sustainability and environmental suitability of the human settlements by evaluating the quality of the natural environment in which the people habitat. There are many researchers who analyse the spaces which are capable of sustainable development, regardless of urban expansion and the movement of people from rural to urban spaces. Remotely sensed data integrated along with GIS can be very useful in monitoring the human settlement and evaluating the habitability analysis (Gamba, 2013). Multi-temporal satellite images of the geographical space helps us in understanding the evolution and development of human settlements from the previous decade till date. There are numerous studies in which the environment suitability for human habitability analyses and human settlement indices were done using the multi-sensor remotely sensed data and GIS techniques (Yuechen et al., 2011; Maimaiti et al., 2017). Regression model based "Human Settlement Index" was first developed by Lu et al., (2008) which was derived from 'DMSP-OLS' and Moderate Resolution Imaging Spectroradiometer (MODIS) data sources. "Human Settlement Environment Index" model was developed using the factors which majorly influences the human settlements, such as terrain, climate, water and land use change (Zhiming et al., 2009; Yuechen et al., 2011; Maimaiti et al., 2017). Human habitability analysis in china was assessed using a "Human Settlement Environment Development Index", which utilises the habitability indicators such as vegetation coverage, Land Surface Temperature (LST), impervious surfaces, slope, wetness and water conditions in analysing the suitable natural environment condition for human habitation (Jishuai et al., 2016).

\footnotetext{
* Corresponding author
} 
As the human habitability analysis involves the integration of multiple factors, it is very difficult to provide approriate weightage based on their relative importance. In this regard, MCE is highly helpful in arriving at good spatial decisions, inspite of the number of factors involved in the evaluation (Carver, 1991). Thus, MCE is used in wide fields of study from site suitability analysis, landslide vulnerable zonation (Rahaman et al., 2017), habitability analysis ( Jishuai et al., 2016), waste management (Delgado et al., 2008) and many more. AHP is one among the many MCE techniques introduced by Saaty, which uses the Pairwise Comparison Matrix (PCM) to acquire the weightage of different factors and their subfactors (Saaty, 1977). Despite a few number of studies on the Human habitability evaluation on the urban settlements, there is no such model for the assessment of habitability index on the coastal region and on the rural settlements based on their natural physical environment. Therefore, this study is aimed at developing a "Natural Human habitation Environment Suitability Index" (NHESI) for evaluating the human habitability of the coastal region by coupling remote sensing data, along with GIS and AHP. Landsat-7 ETM+ (Enhanced Thematic Mapper) and Landsat-8 OLI/TIRS (Operational Land Imager and Thermal Infrared Sensor) with a spatial resolution of $30 \mathrm{~m}$ is used to obtain the five thematic layers such as Land Surface Temperature (LST), vegetation coverage, wetness, water condition and impervious surfaces in order to assess the habitability index of the coastal taluks of Tamil Nadu for the year of 2000 and 2018. To achieve the above said aim, following objectives are followed.

\subsection{Objectives}

a) Preparation of the required thematic layers for the period of both 2000 and 2018 from the remotely sensed data.

b) To assign the weightage and ratings for the selected habitability indicating criteria through AHP and fuzzy linear membership, in order to evaluate the NHESI model.

\section{STUDY AREA AND DATASET}

\subsection{Geographical location of the study area}

The study area, Coastal taluks of Tamil Nadu is the second longest Coastal line, located in the south Indian peninsular region, especially in the south-eastern part of Tamil Nadu. It falls between the latitude of $8^{\circ} 4{ }^{\prime} 42^{\prime \prime} \mathrm{N}$ to $13^{\circ} 33^{\prime} 46^{\prime \prime} \mathrm{N}$ and the longitude of $77^{\circ} 17^{\prime} 22^{\prime \prime} \mathrm{E}$ to $79^{\circ} 52^{\prime} 56^{\prime \prime} \mathrm{E}$ and extends from Chennai in the northern part to Kanniyakumari in the southern part, the two most urbanised coastal cities of Tamil Nadu (Figure 1). It includes a total of 238 taluks from 13 coastal districts of Tamil Nadu and is also the part of Coramandel coast. It covers an area of about $24298.06 \mathrm{sq}$. $\mathrm{km}$. The trade of Tamil Nadu with other international countries takes place in this coastline. The people in the study area majorly indulge themselves in various activities of fishing and aquaculture. This region consists of 4 major ports and 11 minor ports which plays a major role in connecting the coast of Tamil Nadu with rest of the world. Coastal taluks of Tamil Nadu is highly vulnerable to tropical cyclones.

\subsection{Dataset and pre-processing}

In this study, a total number of six scenes with less cloud coverage $(<10 \%)$ from both Landsat-7 ETM+ and Landsat-8
OLI/TIRS acquired in 2000 and 2018 (Table 1.) were obtained from the U.S Geological Survey Global Visualization (GLOVIS) Viewer.

\begin{tabular}{|c|c|c|c|c|}
\hline Satellite & Year & Row/Path & Resolution & Bands used \\
\hline & & $142 / 51$ & & Band 2 \\
& & $142 / 52$ & & Band 3 \\
Landsat-7 & \multirow{2}{*}{2000} & $142 / 53$ & $30 \mathrm{~m}$ & Band 4 \\
(ETM+) & & $142 / 54$ & & Band 5 \\
& & $143 / 53$ & & Band 6 \\
& & $143 / 54$ & & Band 3 \\
& & $142 / 51$ & & Band 4 \\
Landsat-8 & & $142 / 52$ & & Band 5 \\
(OLI/ & \multirow{2}{*}{2018} & $142 / 53$ & $30 \mathrm{~m}$ & Band 6 \\
TIRS) & & $142 / 54$ & & Band 10 \\
& & $143 / 53$ & & Band 11 \\
\hline
\end{tabular}

Table 1. Datasets

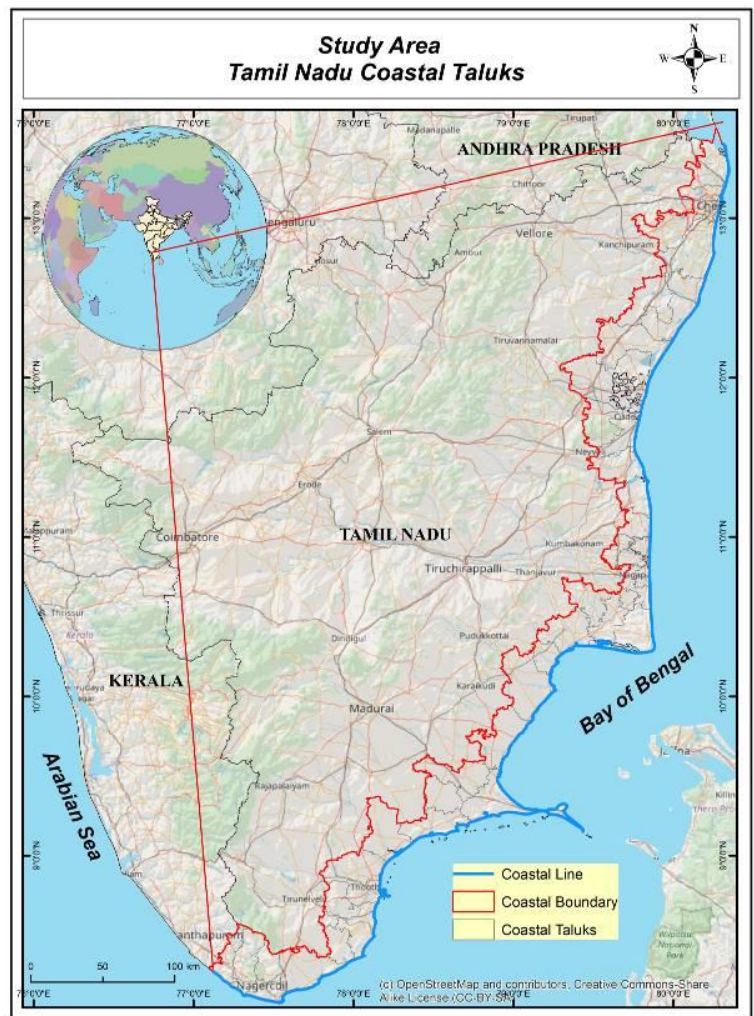

Figure 1. Study Area

The above said satellite images and their bands of different wavelengths have been used to acquire the band ratio techniques based habitability indicators for two different periods (i.e. for 2000 and 2018).

\section{METHODOLOGY}

\subsection{Selection of Band Ratio Indicators for NHESI}

A lot of habitability indicators were used to study the natural environment suitability for human habitation (Zhiming et al. 2009; Maimaiti et al. 2017). In this study, only the spatial layers based on remote sensing data and band ratio techniques were used. All the band ratio image processing was done with the help of raster calculator in ArcGIS 10. In this study, the weightage $W i$ for each criterion is given by AHP and the rating 
$R_{J}$ of their each sub-class is given by fuzzy linear membership. By using this weight and rank finally the NHESI for each considered pixel was calculated by the summation of the weights of each criteria multiplied by each of their classes ratings which are determined using AHP and fuzzy linear membership. The NHESI calculation for each pixel is calculated using raster calculator and are written as follows,

$$
\text { NHESI }=\sum_{i=j}^{n}\left(W_{i} \times R_{j}\right)
$$

The following Figure 2. describes the methodology of the study in detail.

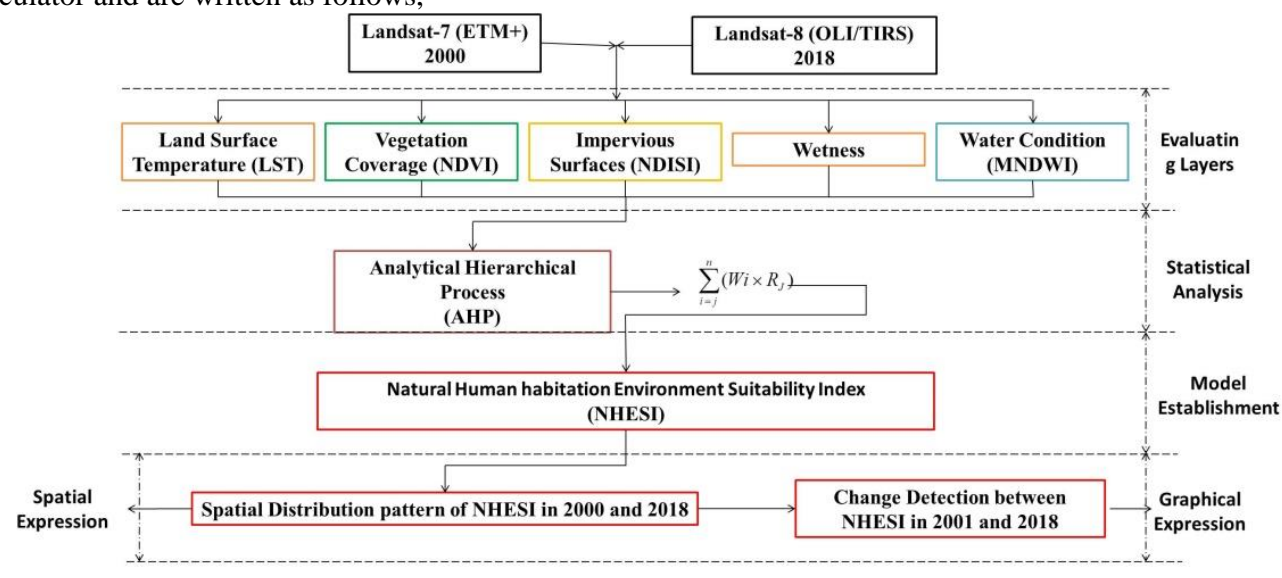

Figure 2. Methodology

The following are the methods and equations by which the above said five selected criteria for this study have been derived.

\subsubsection{Land Surface Temperature (LST)}

The exchange of energy budget between the outgoing long wave terrestrial radiation emitted from the Earth surface and the sensible heat flux of the atmosphere is controlled by the LST (Copertino et al. 2012; Becker and Li, 1990). Every process on the lithosphere, hydrosphere and biosphere are related to the LST (Voogt and Oke, 2003; Pu et al. 2006). Many studies were carried out for acquiring LST from Landsat-7 ETM+ images using Single Channel algorithm (Qin and Karneli, 2000; Lim et al. 2012) and from Landsat-8 TIRS using Split Window (SW) algorithm (Yu et al. 2014; Sahana et al. 2016). In this study, LST from two different Landsat Sensors (ETM+ and TIRS) is predicted by converting the calibrated Digital Numbers (DNs) ranging from 0 to 255 into spectral radiance $L_{\lambda}$ and then to Brightness Temperature $T B$ using the equations and rescaling factors given in Chander et al. (2009). LST was derived from geometrically corrected band 6 in Landsat-7 ETM+ and band 10 and 11 in Landsat-8 TIRS (Table 2.). The following equation is used to convert Digital Numbers $\left(Q_{\text {cal }}\right)$ values into spectral radiance $L_{\lambda}$ in Landsat-7 ETM+ followed by conversion of $L_{\lambda}$ into $T B$ (given in equation 9)

$$
L_{\lambda}=\left(\frac{L M A X_{\lambda}-L M I N_{\lambda}}{Q_{c a l \text { max }}-Q_{c a l \text { min }}}\right) \cdot\left(Q_{c a l}-Q_{c a l \text { min }}\right)+L M I N_{\lambda}
$$

or

$$
\begin{gathered}
L_{\lambda}=G_{\text {rescale }} \times Q_{\text {cal }}+B_{\text {rescale }} \text { where: } \\
G_{\text {rescale }}=\frac{L M A X_{\lambda}-L M I N_{\lambda}}{Q_{\text {cal } \max }-Q_{\text {cal } \min }}
\end{gathered}
$$

$$
B_{\text {rescale }}=\operatorname{LMIN}_{\lambda}-\left(\frac{L M A X_{\lambda}-L M I N_{\lambda}}{Q_{c a l \text { max }}-Q_{\text {cal min }}}\right) \cdot Q_{\text {cal min }}
$$

Where

$L_{\lambda}=$ spectral radiance at the sensor's aperture

$L M A X_{\lambda}=$ Spectral at sensor radiance that is scaled to $Q_{\text {cal max }}$ $\operatorname{LMIN}_{\lambda}=$ Spectral at sensor radiance that is scaled to $Q_{\text {cal min }}$ $Q_{\text {cal }}=$ Quantized calibrated pixel value (DN)

$Q_{\text {cal max }}=$ Maximum quantized calibrated pixel value corresponding to $\operatorname{LMAX}_{\lambda}$ (DN)

$Q_{\text {cal min }}=$ Minimum quantized calibrated pixel value corresponding to $\operatorname{LMIN}_{\lambda}(\mathrm{DN})$

$G_{\text {rescale }}=$ Band specific rescaling gain factor

$B_{\text {rescale }}=$ Band specific rescaling bias factor

\begin{tabular}{|c|c|c|}
\hline \multicolumn{3}{|c|}{ Landsat-7 ETM+ } \\
\hline Rescaling Factor & Band 6 & Units \\
\hline$Q_{\text {cal } \min }$ & 1 & $\mathrm{DN}$ \\
$Q_{\text {cal } \max }$ & 255 & $\mathrm{DN}$ \\
$L M A X_{\lambda}$ & 12.65 & {$[\mathrm{~W} /(\mathrm{m} 2 \mathrm{sr} \mu \mathrm{m})]$} \\
$L_{\lambda} N_{\lambda}$ & 3.2 & {$[\mathrm{~W} /(\mathrm{m} 2 \mathrm{sr} \mu \mathrm{m})]$} \\
$G_{\text {rescale }}$ & 0.037205 & {$[(\mathrm{~W} /(\mathrm{m} 2 \mathrm{sr} \mu \mathrm{m})) / \mathrm{DN}]$} \\
$B_{\text {rescale }}$ & 3.16 & {$[\mathrm{~W} /(\mathrm{m} 2 \mathrm{sr} \mu \mathrm{m})]$} \\
\hline
\end{tabular}

Table 2. Rescaling factors of Landsat-7 ETM+

For retrieving LST from Landsat-8, Split Window (SW) algorithm is used (McMillin, 1975)(Table 3).

$$
\begin{aligned}
& L S T=T B_{10}+C_{1}\left(T B_{10}-T B_{11}\right)+C_{2}\left(T B_{10}-T B_{11}\right)^{2} \\
& +C_{0}+\left(C_{3}+C_{4} W\right)(1-\varepsilon)+\left(C_{5}+C_{6} W\right) \Delta \varepsilon
\end{aligned}
$$

Where,

$C_{0}-C_{6}=$ Split Window Coefficient values

$T B_{10}=$ Brightness Temperature of band 10

$T B_{11}=$ Brightness Temperature of band 11 
$\varepsilon=$ Mean Land Surface Emissivity (LSE)

$\Delta \varepsilon=$ Difference in LSE

$W=$ Atmospheric water vapour content

\begin{tabular}{|c|c|}
\hline Constant & Value \\
\hline$C_{0}$ & -0.268 \\
\hline$C_{1}$ & 1.378 \\
\hline$C_{2}$ & 0.183 \\
\hline$C_{3}$ & 54.300 \\
\hline$C_{4}$ & -2.238 \\
\hline$C_{5}$ & -129.200 \\
\hline$C_{6}$ & 16.400 \\
\hline
\end{tabular}

Table 3. SW algorithm coefficient values

In order to calculate LST for Landsat-8, Top of Atmospheric (TOA) spectral radiance, $\varepsilon$ and $\Delta \varepsilon$ are to be determined by using the following equations.

The TOA spectral radiance is determined by using the following equation in which the band-specific multiplicative rescaling factor and Band specific additive rescaling factor are used (Table 4).

$$
L_{\lambda}=M_{L} \times Q_{\text {cal }}+A_{L}
$$

Where,

$M_{L}=$ Band specific multiplicative rescaling factor

$A_{L}=$ Band specific additive rescaling factor

\begin{tabular}{|c|c|c|c|}
\hline \multicolumn{5}{|c|}{ Landsat-8 TIRS } \\
\hline Rescaling Factor & Band 10 & Band 11 & Units \\
\hline$M_{L}$ & 0.000342 & 0.00342 & $\begin{array}{l}{[(\mathrm{W} /(\mathrm{m} 2 \mathrm{sr}} \\
\mu \mathrm{m}) / \mathrm{DN}]\end{array}$ \\
\hline$A_{L}$ & 0.1 & 0.1 & {$[\mathrm{~W} /(\mathrm{m} 2 \mathrm{sr} \mu \mathrm{m})]$} \\
\hline
\end{tabular}

Table 4. Landsat-8 rescaling factors

In Landsat- 8 for retrieving LST, not only TIRS is utilised but also OLI is also necessary. The LSE is calculated using the NDVI threshold method which is equated as follows;

$L S E=\varepsilon_{s}(1-F V C)+\varepsilon_{v} \times F V C$

$F V C=\frac{N D V I-N D V I_{s}}{N D V I_{v}-N D V I_{s}}$

Where,

$\varepsilon_{s}=$ Soil emissivity

$\varepsilon_{v}=$ Vegetative emissivity

$F V C=$ Fractional Vegetation Cover

The difference in the emissivity $\Delta \varepsilon$ and the mean LSE $\varepsilon$ are derived as follows;

$$
\begin{aligned}
& \varepsilon=\left(\varepsilon_{10}-\varepsilon_{11}\right) / 2 \\
& \Delta \varepsilon=\varepsilon_{10}-\varepsilon_{11}
\end{aligned}
$$

After this for both Landsat-7 and Landsat- 8 following equation with band specific thermal constants are used in order to determine and convert the TOA of spectral radiance $L_{\lambda}$ into Brightness Temperature $T B$ in Kelvin.

$$
T B=\frac{K_{2}}{\operatorname{Ln}\left[\left(\frac{K_{1}}{L_{\lambda}}\right)+1\right]}
$$

Where,

$K_{1}$ and $K_{2}=$ band-specific thermal conversion constant

\begin{tabular}{|c|c|c|c|}
\hline Sensor & \multicolumn{2}{|c|}{ Landsat-8 TIRS } & Landsat-7 ETM+ \\
\hline $\begin{array}{c}\text { Thermal } \\
\text { constant }\end{array}$ & Band 10 & Band 11 & Band 6 \\
\hline$K_{1}$ & 1321.08 & 1201.14 & 666.09 \\
\hline$K_{2}$ & 777.89 & 480.89 & 1282.71 \\
\hline
\end{tabular}

Table 5. Thermal Constant $K_{1}$ and $K_{2}$

The LST from the Kelvin units is converted into celcisus by subtarcting 273.15 from the derived TB.

$L S T_{\text {Celcius }}=T B-273.15$

\subsubsection{Vegetation Coverage}

Vegetation coverage reflects the amount of vegetation seen in a spatial region. The interaction between humans and natural vegetation is an important process as it develops habitation with eco-friendly environment where the co-existence of the human and ecological processes prevails simultaneously and is governed by humans to attain a sustainable development (Marzluff et al. 2008). Considering the measure of vegetative coverage is very important in analysing the natural environment suitability for human settlement. In this study, the area covered by the vegetative region is measured by using the famous and first of its kind Vegetation Index (VI): Normalised Differential Vegetation Index (NDVI) which is a normalised band ratio of Near-Infrared (NIR) and Red (R) (Rouse et al. 1973). The respective bands of Landsat-7 and Landsat- 8 used for calculating the NDVI is given in the Table 6.

$$
N D V I=\frac{N I R-R E D}{N I R+R E D}
$$

\begin{tabular}{|c|c|c|}
\hline Sensor & NIR band & Red band \\
\hline Landsat-7 ETM+ & Band 4 & Band 3 \\
\hline Landsat-8 OLI & Band 5 & Band 4 \\
\hline
\end{tabular}

\subsubsection{Wetness}

Table 6. Bands for retrieving NDVI

The wetness of the study area is calculated by using the following equation (Gang and Dongsheng, 2012; Jishuai et al. 2016). Wetness index is a normalised band ratio of Near Infrared (NIR) and Shortwave Infrared (SWIR).

$W e t=\frac{N I R-S W I R}{N I R+S W I R}$

\subsubsection{Water}

There are many band ratio techniques to extract the water features from the remotely sensed data, eg. NDWI (Mcfeeters, 1996), NDWI $I_{\mathrm{GAO}}(\mathrm{Gao}, 1996)$ and MNDWI (Xu, 2006). In this study, the water features are extracted using the following equation developed by ( $\mathrm{Xu}, 2006)$. Modified Normalised Difference Water Index (MNDWI) is a normalised band ratio of Green and Middle Infrared (MIR). The respective bands of Landsat-7 and Landsat- 8 for calculating the MNDWI is given in the Table 7.

MNDWI $=\frac{\text { Green }- \text { MIR }}{\text { Green }+M I R}$
\begin{tabular}{|c|c|c|}
\hline Sensor & Green band & MIR band \\
\hline Landsat-7 ETM+ & Band 2 & Band 5 \\
\hline Landsat-8 OLI & Band 3 & Band 6 \\
\hline
\end{tabular}

\subsubsection{Impervious surfaces}

Impervious surfaces are a major indicator of environmental quality, anthropogenic features and the degree of urbanisation (Arnold and Gibbons, 1996). They are mainly urban features through which water cannot penetrate into the soil (Weng, 2012). In this study, equation developed by (Xu, 2010) is utilised for calculating the Normalised Difference Impervious 
Surface Index (NDISI). The respective bands of Landsat-7 and Landsat- 8 for calculating NDISI is given in the Table 8 .

$$
N D I S I=\frac{T I R-[(W I+N I R+M I R 1) / 3]}{T I R+[(W I+N I R+M I R 1) / 3]}
$$

Where

$T I R=$ Thermal Infrared

$W I=$ Water Index

$M I R=$ Middle Infrared

In this equation WI is derived from the MNDWI of ( $\mathrm{Xu}, 2006$ ).

\begin{tabular}{|c|c|c|c|}
\hline Sensor & TIR & MIR band & $\begin{array}{c}\text { NIR } \\
\text { band }\end{array}$ \\
\hline Landsat-7 ETM+ & Band 6 & Band 5 & Band 4 \\
\hline Landsat-8 OLI/TIRS & Band 10,11 & Band 6 & Band 5 \\
\hline
\end{tabular}

Table 8. Bands for retrieving MNDWI

\subsection{Analytical Hierarchical Process (AHP)}

The above considered five criteria were given weightage using AHP which was a semi-qualitative method developed by Saaty (1977). The first level weightage is given by using the Pairwise Comparison Matrices (PCM) of AHP where each criteria is rated against each other factor by assisgning a value of 1 to 9 for the intersecting cells based on the relative importance of each criteria (Saaty, 1980). In this study, PCM consists of 25 boxes where only 12 boxes are to be filled since five criteria is considred in this study. In this study, fundamental scale for PCM of Saaty (1980) have been used to give weightage for the criteria. The consistency in the PCM of AHP is checked by using Consistency Ratio (CR), which is based on the number of parameters considered where, $\mathrm{CR}$ is a fraction of Consistency Index $(\mathrm{CI})$ and Random consistency Index (RI). Often the CR less than 0.1 is accepted and the CR greater than 0.1 is rejected (Saaty, 1987).

$$
C R=\frac{C I}{R I}
$$

The $\mathrm{CI}$ is expressed as follows,

$$
C I=\frac{\lambda_{\max }-n}{n-1}
$$

Where,

$\lambda_{\max }=$ Principal Eigen value of the matrix $n=$ order of the matrix

For the derivation of RI, a sample of randomly generated reciprocal matrices is utilised with a scale of $1 / 9,1 / 8, \ldots, 8$ and 9. In this study, the first level weightage for criteria were given by AHP and the second level weightage for each class were given using fuzzy linear memebership.

\section{RESULT AND DISCUSSION}

\subsection{Spatial distribution of various criteria}

The LST, vegetation coverage, wetness, water condition and impervious surfaces have been derived for 2000 (Figure 3.) and 2018 (Figure 4.) by following the above said methodology and are categorised into different classes based on their characteristics and their impact on the natural environment and human habitation suitability. The final result for NHESI in the coastal taluks of Tamil Nadu during the period of 2000 and 2018 is obtained by applying the weightage and rating for each and every criterion and their classes derived from AHP and fuzzy linear membership in the raster calculator. The classes of each criterion were given a rating of 0.2 to 1 using fuzzy linear membership based on their significance. The weightage and the rating for each criterion and their classes have been given in the Table 9 .

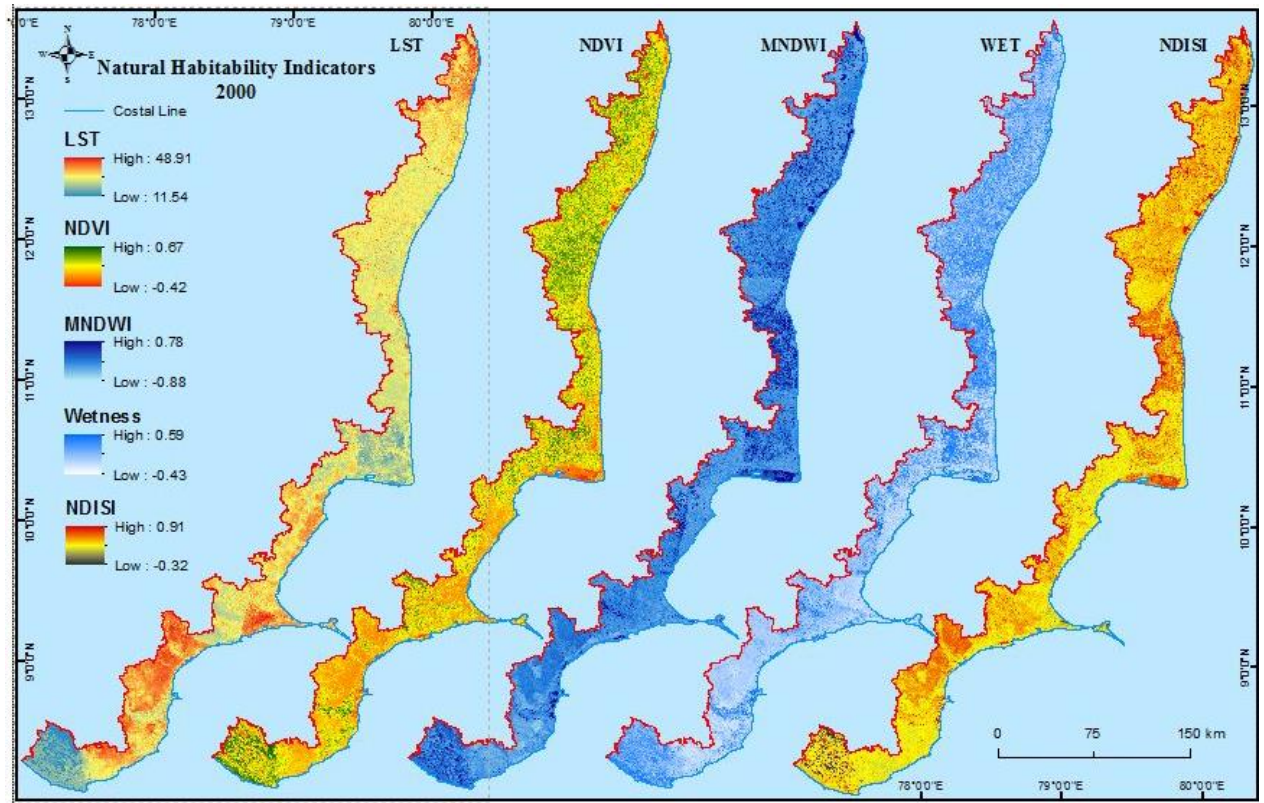

Figure 3. Natural Habitability Indicators 2000

Since LST mostly influences the nature of the human environment, it has been given a highest weightage of 0.406 . The LST ranges between $44.56^{\circ} \mathrm{C}$ and $16.77^{\circ} \mathrm{C}$ in 2000 , while this ranges is seen increased in 2018 where the LST ranges between $48.91{ }^{\circ} \mathrm{C}$ and $11.54^{\circ} \mathrm{C}$, which clearly shows the decrease in the range of LST from 2000 to 2018. The highest rating has been given for $25-30^{\circ} \mathrm{C}$ which is the best condition suitable for human habitation. Vegetation coverage which has been calculated by using NDVI is given a second highest weightage of 0.328 , due to its important role in maintaining the balance in the nature. Vegetation coverage of the study ranges between 0.67 and -0.42 during 2000, and ranges between 0.59 and -0.31 during 2018 respectively. The highest rating is given for the medium class which ranges between 0.16 and 0.21 . The wetness of the study area has been calculated by using wetness index and is given a weightage of 0.041 which ranges between 0.598 and -0.4320 in 2000 and between 0.55 and -0.64 during 2018 respectively. The wetness class ranging between -0.01 and 0.04 is given the highest rating. Water condition has been given a weightage of 0.146 , since the evolution of human and natural 
environment is mainly confined with the presence of water. The water condition of the study area is calculated using MNDWI which ranges between 0.78 and -0.88 in 2000 and ranges from 0.60 to -0.72 in 2018 . Due to its ability to point out the urban expansion impervious surfaces were given a weightage of 0.079 respectively. The impervious surfaces of the study area have been calculated using NDISI which ranges between -0.91 and 0.32 in 2000 and between -0.98 and -0.99 in 2018 respectively.

The final NHESI results for both 2000 and 2018 have been classified into four classes viz. habitable, moderately habitable, marginally habitable and uninhabitable regions based on the habitability index (Figure $5 \&$ Figure 6). The final results from NHESI shows that in the year 2000, habitable region are seen sparsely spread out everywhere in the study area apart from the regions of water bodies and reserved forests which covers an area of about $13902.9 \mathrm{~km}^{2}$, whereas the moderately habitable and marginally habitable region is seen surrounding the habitable region and covers an area of about $4695.2 \mathrm{~km}^{2}$ and $2067 \mathrm{~km}^{2}$ respectively. The uninhabitable region are seen in the southern part, especially in the districts of Kannyakumari, Tuticorin, Nagappatinam and also seen in the northern most part of Thiruvallur which extends over an area of and $3632.26 \mathrm{~km}^{2}$ respectively. The Water bodies and the parts with high vegetation especially the reserved forests were seen in the uninhabitable region of the study area.

\begin{tabular}{|c|c|c|}
\hline $\begin{array}{c}\text { Criteria and their } \\
\text { Weightage }\left(\mathbf{W}_{\mathbf{i}}\right)\end{array}$ & Sub-Class & Rating $\left(\mathbf{R}_{\mathbf{j}}\right)$ \\
\hline & $>35^{\circ} \mathrm{C}$ & 0.4 \\
Land Surface & $30-35^{\circ} \mathrm{C}$ & 0.8 \\
Temperature & $25-30^{\circ} \mathrm{C}$ & 1 \\
$\boldsymbol{W i}=\mathbf{0 . 4 0 6}$ & $20-25^{\circ} \mathrm{C}$ & 0.6 \\
& $<20^{\circ} \mathrm{C}$ & 0.2 \\
\hline & Very High & 0.8 \\
Vegetation coverage & High & 0.6 \\
$\boldsymbol{W i = 0 . 3 2 8}$ & Medium & 1 \\
& Low & 0.4 \\
& Very low & 0.2 \\
\hline Wetness & Very High & 0.8 \\
$\boldsymbol{W i = 0 . 0 4 1}$ & High & 0.6 \\
& Medium & 0.2 \\
& Low & 1 \\
& Very low & 0.4 \\
\hline Water condition & Very High & 0.2 \\
$\boldsymbol{W i}=\mathbf{0 . 1 4 6}$ & High & 0.4 \\
& Medium & 0.8 \\
& Low & 1 \\
& Very low & 0.6 \\
\hline Impervious surfaces & High & 0.33 \\
$\boldsymbol{W i = 0 . 0 7 9}$ & Medium & 0.66 \\
\hline
\end{tabular}

Table 9. Weightage and rating derived using AHP and fuzzy linear membership

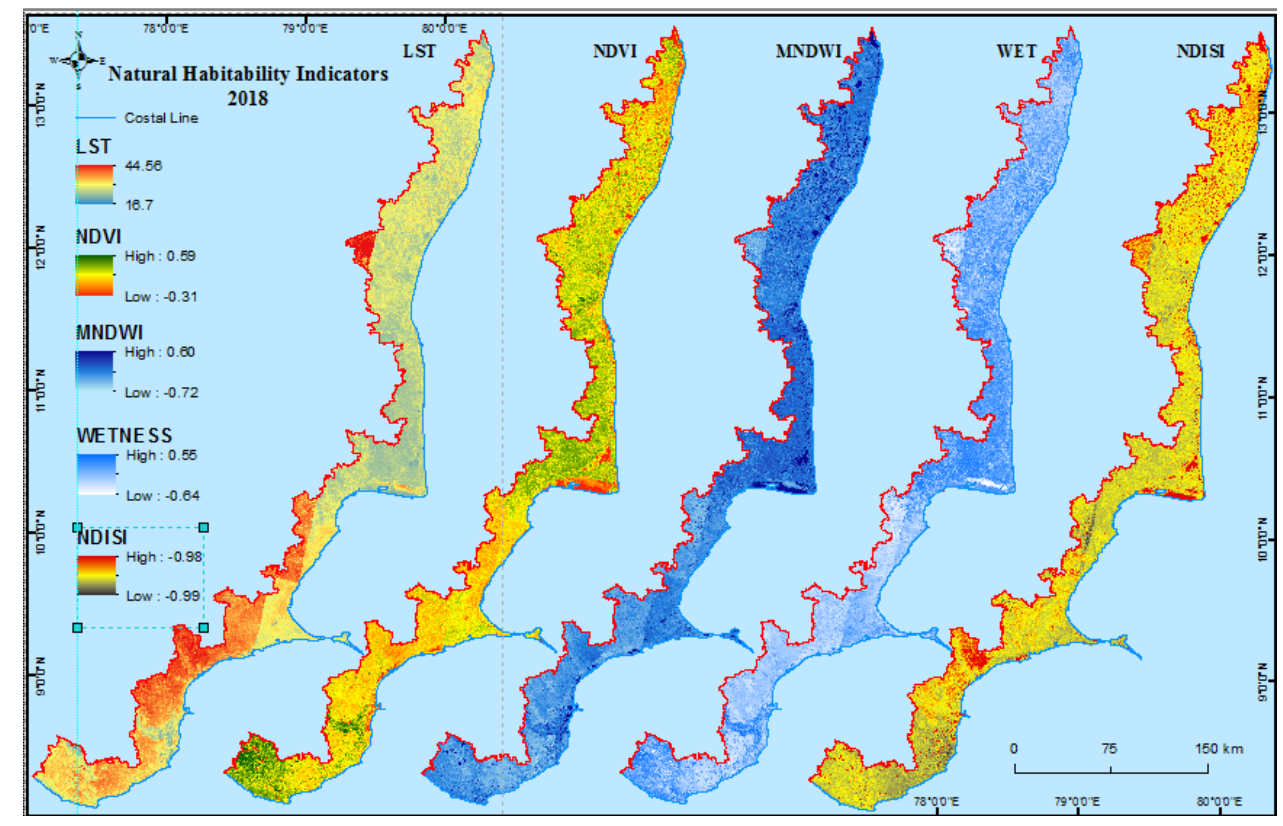

Figure 4. Natural Habitability Indicators 2018

In the period of 2018, the habitable region of the study area has been decreased for about $6176 \mathrm{~km}^{2}$ from 2000 which constitutes nearly $25.41 \%$ decrease in the percentage of natural environment which is suitable for human habitation. A decrease in the habitable regions is seen the southern districts of Tamil Nadu which may be due to the effect of decreasing natural suitable environment for human habitation. Comparing both the years, moderately habitable region have been increased in a meagre area where as marginally habitable and uninhabitable region have been tremendously increased by an area of about $4813.9 \mathrm{~km}^{2}$ and $1212.8 \mathrm{~km}^{2}$ respectively (Figure 7).

\begin{tabular}{|c|r|r|}
\hline NHESI Suitability Class & $\begin{array}{c}\text { Area in 2000 } \\
\left(\mathbf{k m}^{\mathbf{2}}\right)\end{array}$ & $\begin{array}{c}\text { Area in 2018 } \\
\left(\mathbf{k m}^{\mathbf{2}}\right)\end{array}$ \\
\hline Habitable & 13902.9 & 7726.9 \\
\hline Moderately habitable & 4695.2 & 4844.5 \\
\hline Marginally habitable & 2067.7 & 6881.6 \\
\hline Uninhabitable & 3632.26 & 4845.06 \\
\hline
\end{tabular}

Table 10. NHESI Suitability class 


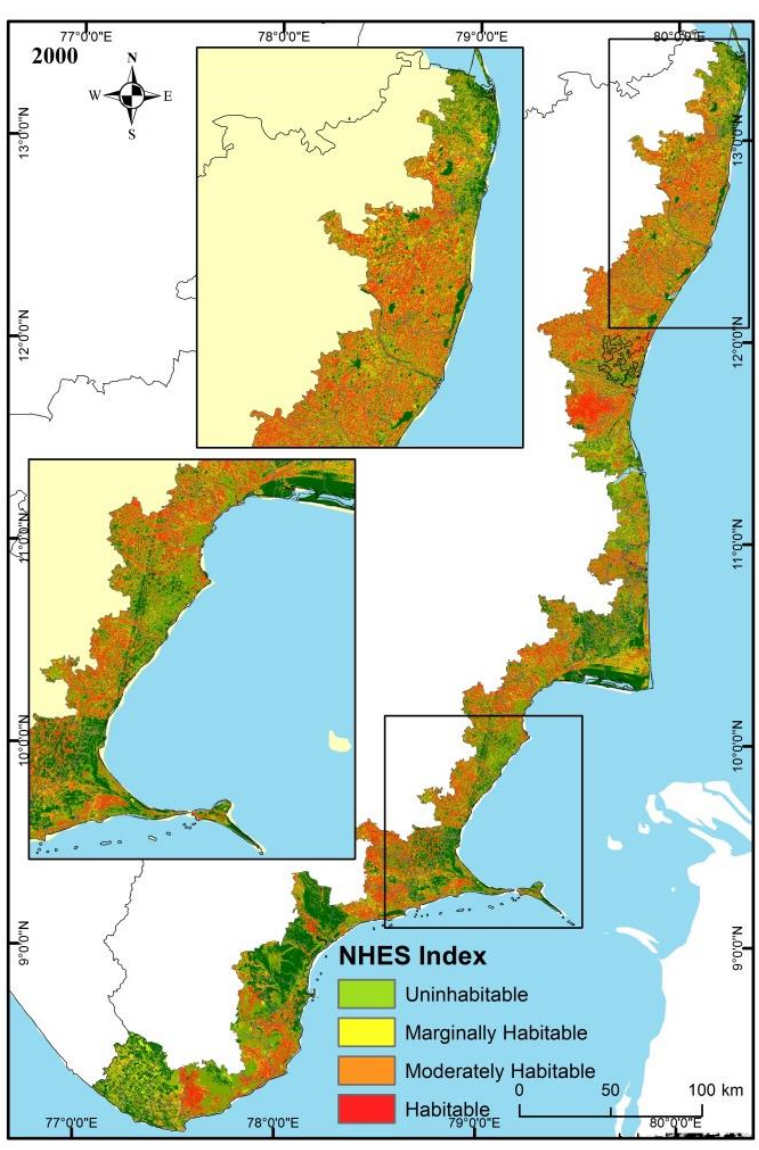

Figure 5. NHES Index 2000

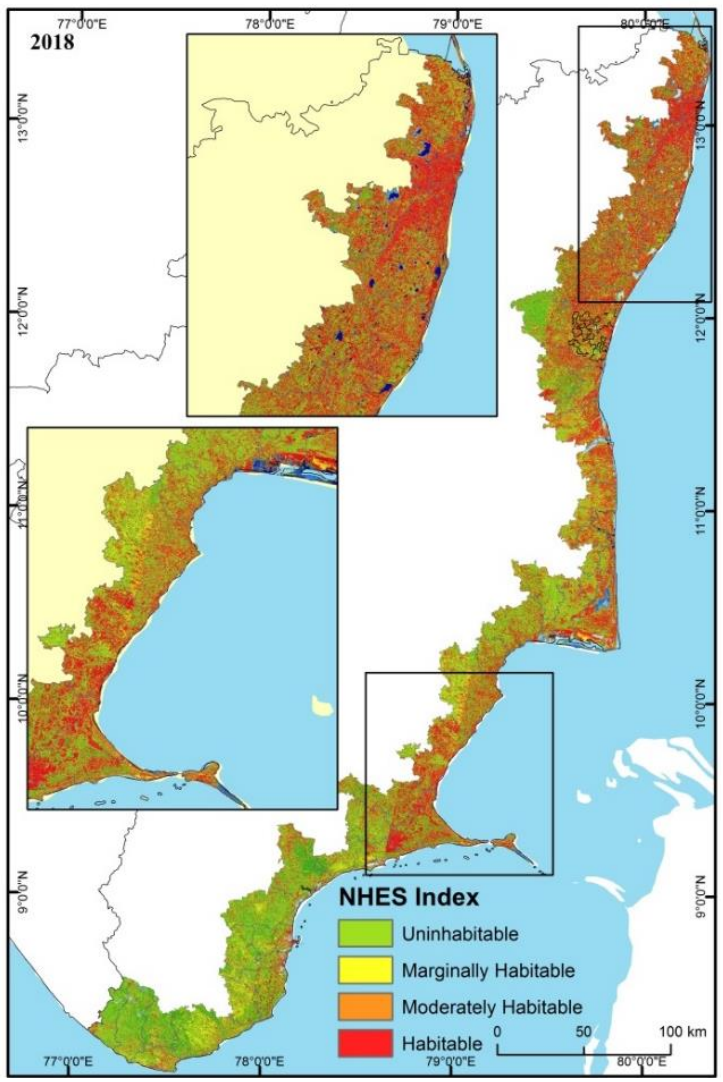

Figure 6. NHES Index 2018

\begin{tabular}{|l|r|r|}
\hline $\begin{array}{c}\text { NHESI Suitability } \\
\text { Class }\end{array}$ & $\begin{array}{c}\text { Changes in Area } \\
\text { from } \mathbf{2 0 0 0} \text { \& } \\
\mathbf{2 0 1 8} \mathbf{( k m}^{\mathbf{2}}\end{array}$ & $\begin{array}{c}\text { Changes in Area } \\
\text { from 2000 \& } \\
\mathbf{2 0 1 8}(\mathbf{\%})\end{array}$ \\
\hline Habitable & -6176 & -25.4177 \\
\hline Moderately habitable & 149.3 & 0.614452 \\
\hline Marginally habitable & 4813.9 & 19.81187 \\
\hline Uninhabitable & 1212.8 & 4.991345 \\
\hline
\end{tabular}

Table 11. Area changes in $\mathrm{km}^{2}$ and $\%$

\section{Habitability changes (\%)}

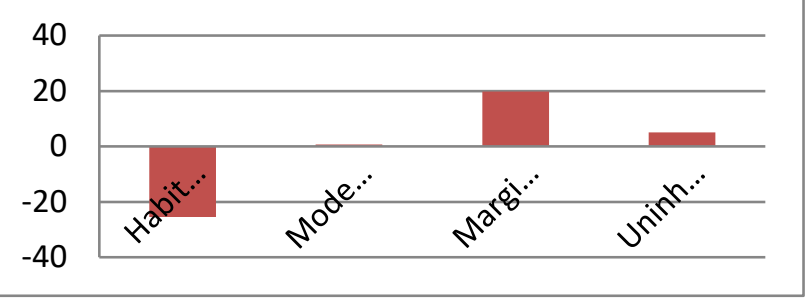

Figure 7. Habitability changes in \%

\section{CONCLUSION}

This study utilises the five band ratio factors retrieved from the $30 \mathrm{~m} \times 30 \mathrm{~m}$ resolution Landsat data $(\mathrm{ETM}+$ and OLI/TIRS) to analyse the suitable natural environment for human habitation for people in the coastal taluks of Tamil Nadu by using a NHESI model based on the selected five criteria which were considered as the natural environment habitability indicators. The resultant from the study of NHESI in the coastal taluks of are as follows,

1) There is a decrease in the amount of suitable natural environment for human habitation based on the factors considered in this study.

2) This decrease in the suitable natural environment urges the people living in those coastal taluks of Tamil Nadu to increase the green space within and outside the city limits.

3) The geographical spaces which are already been utilised by the people should be preserved.

The results from this study are totally based on the spatial factors derived from remote sensing data based band ratio techniques, this same kind of study with the usage of further more spatial factors and high resolution images are encouraged to get improved and better results. This kind of habitability study will also help the researchers, decision makers and government agencies in creating awareness and adopting policies in the spatial planning of human land utilization for habitability.

\section{REFERENCES}

Arnold, C., \& Gibbons, C. (1996). Impervious surface coverage: The emergence of a key environmental indicator. Journal of the American Planning Association, 62, pp. 243-258.

Becker, F., \& Li , Z.-L. (1990). Temperature independent spectral indices in thermal infrared bands. Rem. Sens. Environ., 32, pp. 17-33.

Carver, S. (1991). Integrating multi-criteria evaluation with geographical information systems. International Journal of Geographical Information, pp. 321-339.

Chander, G., Markham, B. L., \& Helder, D. L. (2009). Summary of current radiometric calibration coefficients for Landsat MSS, TM, 
ETM+, and EO-1 ALI sensors. Remote Sensing of Environment, 113, pp. 893-903.

Choguill, C. L. (1996). Toward sustainability of human settlements. Habitat International, 20(3), pp. 5-8.

Copertino, V., Pierro, M. D., Scavone, G., \& Telesca, V. (2012) Comparison of algorithms to retrieve LST from LANDSAT-7 ETM+ IR data in the Basilicata Ionian band. Tethys Journal of Weather and Climate of the Western Mediterranean, 9, pp. 1-17.

Delgado, O., Mendoza, M., Granados, E., \& Geneletti, D. (2008) Analysis of land suitability for the siting of inter-municipal landfills in the Cuitzeo Lake Basin, Mexico. Waste Management, pp. 1137-1146.

Doxiadis, C. A. (1968). Man's Movement and His City. SCIENCE, 162, pp. 326-334.

Doxiadis, C. A. (1970). Ekistics, the Science of Human Settlements Science, 170 , pp. 393-404.

Gamba, P. (2013). Human settlements: a global challenge for EO data processing and interpretation. Proceedings of the IEEE, 101(3), pp. $570-581$.

Gang, W., \& Dongsheng, G. (2012). Effects of vegetation cover and normalized difference moisture index on thermal landscape pattern: a case study of Guangzhou, South China. China Journal of Applied Ecology, 23(9), pp. 2429-2436.

Gao, B. (1996). NDWI-a normalized difference water index for remote sensing of vegetation liquid water from space. Remote Sensing of Environment, 58, pp. 257-266.

Goldewijk, K. K., \& Ramankutty, N. (2004). Land cover change over the last three centuries due to human activities: The availability of new global data sets. GeoJournal, pp. 335-344.

Jishuai, Z., Shufang, T., Kun, T., \& Peijun, D. (2016). Human settlement analysis based on multi-temporal remote sensing data: a case study of Xuzhou City, China. Chinese Geographical Science, 26(3), pp. 389-400.

Lim, H., Jafri, M. M., Abdullah, K., \& AlSultan, S. (2012). Application of a Simple Mono Window Land Surface Temperature Algorithm from Landsat ETM+. Sains Malaysiana, 41(7), pp. 841-846.

Lu, D., Tian, H., Zhou, G., \& Ge, H. (2008). Regional mapping of human settlements in southeastern China with multisensor remotely sensed data. Remote Sensing of Environment, pp. 3668-3679.

Maimaiti, A., Wang, L., Zhang, J., \& Song, Z. (2017). Environmental suitability evaluation for human settlements in Bosten Lake Basin. IOP Conference Series: Earth and Environmental Science, pp. 1-5.

Marzluff, J., Shulenberger, E., \& Endlicher, E. (2008). Urban ecology: an international perspective on the interaction between humans and nature. Springer. New York.

Mcfeeters, S. (1996). The use of normalized difference water index (NDWI) in the delineation of open water features. International Journal of Remote Sensing, 17, pp.1425-1432.

McMillin, L. (1975). Estimation of sea surface temperatures from twoinfrared window measurements with different absorption. $J$ Geophys Res, 80, pp. 5113-5117

Neumann , B., Vafeidis, A. T., Zimmermann, J., \& Nicholls, R. J. (2015). Future Coastal Population Growth and Exposure to Sea-Level Rise and Coastal Flooding - A Global Assessment. Plos One, 10(6).

Pu, R., Gong, P., Michishita, R., \& Sasagawa, T. (2006). Assessment of multi-resolution and multi-sensor data for urban surface temperature retrieval. Remote Sensing of Environment, 104, pp. 211-225.
Qin, Z., \& Karneli, A. (2001). A mono-window algorithm for retrieving land surface temperature from Landsat TM data and its application to the Israel-Egypt border region. International Journal of Remote Sensing, 22(18), pp. 3719-3746.

Rahaman, S., \& Aruchamy, S. (2017). Geoinformatics based landslide vulnerable zonation mapping using analytical hierarchy process (AHP), a study of Kallar river sub watershed, Kallar watershed, Bhavani basin, Tamil Nadu. Model. Earth Syst. Environ., 3(41), pp. 13.

Report Of The United Nations Conference On Environment And Development-Promoting Sustainable Human Settlement Development. (1992). UNO, Rio de Janeiro.

Rouse, J., Haas, R., Well, J., \& Deering, D. (1973). Monitoring Vegetation Systems in the Great plains with ERTS. Third ERTS-1 Symposium, pp. 309-317.

Saaty, T. (1977). A scaling method for priorities in higherarchial structures. Journal of Mathematical Psychology, 15(3), pp. 234-281.

Saaty, T. (1980). The Analytical Hierarchy Process. New York: McGraw Hill.

Saaty, T. (1987). The analytic hierarchy process - what it is and how it is used. Mathematical Modelling, pp. 161-167.

Sahana, M., Ahmed, R., \& Sajjad, H. (2016). Analyzing land surface temperature distribution in responseto land use/land cover change using split window algorithmand spectral radiance model in Sundarban Biosphere Reserve,India. Model. Earth Syst. Environ., pp. 11.

Transforming Our World: The 2030 Agenda For Sustainable Development (2016). United Nations.

Voogt, J., \& Oke, T. (2003). Thermal remote sensing of urban climates. Remote Sensing of Environment, 86, pp. 370-384

Weng, Q. (2012). Remote sensing of impervious surfaces in the urban areas: Requirements, methods, and trends. Remote Sensing of Environment, 117, pp. 34-49.

$\mathrm{Xu}$, H. (2006). Modification of normalised difference water index (NDWI) to enhance open water features in remotely sensed imagery. International Journal of Remote Sensing, 27(14), pp. 3025-3033.

$\mathrm{Xu}$, H. (2010). Analysis of Impervious Surface and its Impact on Urban Heat Environment using the Normalized Difference Impervious Surface Index (NDISI). Photogrammetric Engineering \& Remote Sensing, 76(5), pp. 557-565.

Yu, X., Guo, X., \& Wu, Z. (2014). Land Surface Temperature Retrieval from Landsat 8 TIRS-Comparison between Radiative Transfer Equation-Based Method, Split Window Algorithm and Single Channel Method. Remote Sensing, 6, pp. 9829-9852.

Yuechen, L., Chunxia, L., Hong, Z., \& Xin, G. (2011). Evaluation on the human settlements environment suitability in the Three Gorges Reservoir Area of Chongqing based on RS and GIS. Journal of Geographical Sciences, pp. 346-358.

Zhiming, F., Yanzhao, Y., Dan, Z., \& Yan, T. (2009). Natura environment suitability for human settlements in China based on GIS Journal of Geographical Sciences, 19, pp. 437-446. 